\title{
The Role of Music in the Advancement of Civilization
}

\author{
Kerry Hart
}

\begin{abstract}
An individual's self-knowledge (i.e., self-identity) is one of the most humanizing values of civilization. In this study, music's interrelatedness with feeling, value, and self-identity is explained and analyzed. The nurturance and furtherance of an individual's self-identity is synonymous with the individual's mental and spiritual growth. The way in which an individual can grow mentally and spiritually through music is investigated by using the Bahá'í writings on music as a foundation for philosophical inquiry. The use of the Bahá'í writings helps to explain and clarify the more than two-thousand-year-old mystery of how music affects the human soul.
\end{abstract}

\section{Résumé}

La connaissance de soi (ou l'image personnelle) est une des valeurs les plus humanisantes de la civilisation. Dans cette étude, l'auteur explique et analyse la relation entre la musique, les sentiments, la valeur et l'image personnelle. L'enrichissement et le développement de l'image personnelle est synonyme de progrès mental et spirituel. En prenant les écrits bahá'ís sur la musique comme fondement philosophique, l’auteur étudie les moyens par lesquels une personne peut croître mentalement et spirituellement par la musique. Le recours aux écrits bahá'ís aide à comprendre et clarifier le mystère, vieux de plus de deux mille ans, de l'effet produit par la musique sur l'âme humaine.

\section{Resumen}

El conocimiento de sí mismo (v. gr., auto-identidad) es uno de los valores mas humanizantes de la civilización. En este estudio el entrelace de la música con el sentimiento, el aprecio, y la auto-identificación se explica y analisa. El fomento y promoción de la auto-identidad del individuo es paralela a su desarrollo mental y espiritual. Se investiga el mode en que el individuo pueda crecer mentalmente y espiritualmente mediante el uso de los escritos Bahá'ís como fundamento para la indagación filosófica. El uso de los escritos Bahá'ís ayuda a explicar y aclarar aquel misterio de mas de dos mil años de como la música afecta el alma humana.

\section{Introduction}

工 or more than two thousand years philosophers have attempted to solve the mystery of the effects of music on the 1 human soul. The effect of music on individual souls is considered relevant to the nature and function of music in society. In ancient Greek music, for example, the modes (scales) were given ethical characteristics commonly known as the Doctrine of Ethos. Numerous modes were used by the ancient Greeks to help individuals build character, attain virtues, and influence moral behavior. One of the Greek modes, the Dorian mode, stood for mental strength and fortitude. Phrygian melodies were considered ecstatic, sensual, and passionate.

The way in which philosophers have attempted to explain the phenomenon of music in the culture of humanity has varied throughout history. Pythagorus (550 B.C.) explained music as an expression of a universal harmony. Plato (400 B.C.) considered music a means of social and political education. Boethius (d. 524) formulated a threetiered classification of music that lasted more than ten centuries: the Pythagorean harmony of the universe; the harmony of the human soul and body; and music as actual sound. In the seventeenth century, Johannes Kepler (1571-1630) related musical tones and intervals to the astronomical movement of the planets; and Gottfried W. Leibnitz (1646-1716) described music as an unconscious exercise in arithmetic.

With the advent of psychology in the nineteenth century, philosophers began relating music to a psychological system of aesthetics. Arthur Schopenhauer (1788-1860) considered music the expression of human emotion in an abstract interpretation of metaphysical ideas. The nineteenth-century concept of aesthetics as an emotional aspect of music is generally recognized by twentieth-century philosophers and aestheticians as the cornerstone for current aesthetic thought in music. 
Twentieth-century philosophers and aestheticians have redefined the emotional experience of music as an experience in feeling. The term feeling is used by contemporary aestheticians to imply a broader scope than emotion. The music educator Bennett Reimer defines feeling as "every possible mode of responsiveness of which humans are capable" (Philosophy 38). One twentieth-century aesthetician, Susanne Langer, described feeling in music as analogous to the entirety of human existence. In a 1953 essay on art symbols and feeling, Langer wrote:

The tonal structures we call "music" bear a close logical similarity to the forms of human-feeling forms of growth and attenuation, flowing and stowing, conflict and resolution, speed, arrest, terrific excitement, calm, or subtle activation and dreamy lapses—not joy and sorrow perhaps, but the poignancy of either and both — the greatness and brevity and eternal passing of everything vitally felt. Such is the pattern or logical form, of sentience; and the pattern of music is that same form worked out in pure, measured sound and silence. Music is a tonal analogue of emotive life. (Feeling 27)

Langer used her analogy to attempt an explanation and objectification of feeling through art (i.e., music) symbols in order to understand the significance of music in psychological terms. Langer was severely criticized by other aestheticians, however, for not explaining the logical connection between the work of art and the life of feeling that provides knowledge.

In light of the philosophical attempts to explain the effects of music on the human soul, a Bahá'í perspective on music is of considerable interest. Bahá'u'lláh stated:

Arts, crafts and sciences uplift the world of being, and are conducive to its exaltation. Knowledge is as wings to man's life, and a ladder for his ascent. Its acquisition is incumbent upon everyone. The knowledge of such sciences, however, should be acquired as can profit the peoples of the earth, and not those which begin with words and end with words. (Epistle 26)

'Abdu'l-Bahá stated that "music is regarded as a praiseworthy science at the Threshold of the Almighty" (Compilation 5); and in another passage stated that "in this new age... music, sung or played, is spiritual food for soul and heart" (Selections 112).

By using the writings of the Bahá'í Faith as a basis for philosophical inquiry, a determination will be made to explain how music helps an individual grow mentally and spiritually (i.e., how the knowledge of music becomes the means for "man's ascent") and why music is an art that can profit the peoples of the world. By using the writings of the Bahá'í Faith as a basis for this study, the philosophical attempts to explain the effects of music on the human soul will be clarified and enhanced.

\section{The Relation between Feeling and Music}

The Bahá'í writings affirm Susanne Langer’s notion that music is analogous to human feeling. 'Abdu'l-Bahá states that "although sounds are but vibrations in the air which affect the ear's auditory nerve, and these vibrations are but chance phenomena carried along through the air, even so, see how they move the heart" (Selections 147). The difference between Langer's concept of feeling and that of 'Abdu'l-Bahá, is that Langer views the concept of "feeling” as the feeling of human existence symbolized in music; whereas 'Abdu'l-Bahá implies that feeling is an integral component of the music itself-derived from the vibrations in the air.

Abdu'l-Bahá's statement that the vibrations of sound have an affect on the heart may be explained scientifically to demonstrate how feeling and music are interrelated. By relying on the principles of the twentieth-century philosopher Alfred North Whitehead, the connectedness between a musical tone and feeling can be described. The musical tone, as a sensation of pitch, quality, and intensity, may be analyzed into its fundamental tone and a selection of its overtones. ${ }^{1}$ The fundamental and its overtones have their own intensities. The pattern of intensities can be analyzed as an abstract qualitative pattern of the relative intensities and the absolute intensity, which is the

1. The fundamental tone and overtones may be defined on mathematical principles. When a tone is sounded on a stringed instrument, the string vibrates simultaneously as a whole string, and in sections of one-half, one-third, one-fourth, ad infinitum of its total length. The overtones (also called harmonics) are the secondary vibrations of one-half, one-third, one-fourth, etc., which have a much smaller amplitude than the fundamental. The overtones, which have a different pitch from the fundamental, are always present with the sounding of a single tone but are nearly imperceptible to the human ear. 
perceived volume. Each relative intensity of the musical tone is perceived as a sensation. The perceived volume (absolute intensity) is a feeling derived from the synthesis of the sensations associated with the relative intensities (Process 234).

The way in which an individual transforms the musical tone into feeling is by integrating the nexus of relative and absolute intensities. In a physical context, the sensations associated with a musical tone can be explained on the same principle as the steady endurance of matter. Each element in the universe is a vibratory ebb and flow of energy or activity. The activity in a musical composition is an organized system of tones. Each tone is an organized system of vibratory streaming energy. The duration of the musical composition associated with the tone involves a flux with a quantitative flow and definite direction as it passes from past to future. In the physical theory of alternate forms of energy, energy can be transformed from one form to another. The transformation from a musical tone to feeling may undergo the same transformation as energy. Whitehead generalizes this concept as follows:

If we substitute the term "energy" for the concept of a quantitative emotional intensity, and the term "form of energy" for the concept of specific form of feeling and remember that in physics "vector" means definite transmission from elsewhere, we see that this metaphysical description of the simplest elements... agrees absolutely with the general principles according to which the notions of modern physics are framed. (Process 116)

In the transformation of the sensation perceived from the audition of a musical tone to the mental operation of "feeling," the integration of feeling, in a physical sense, is an integration of qualitative and quantitative auditory contributions that result from a reaction to the various nerve routes of the body. The individual reckons qualities of aversion or pleasure, joy or distaste, as required by the mental operation involved in the audition of musical tones. The qualities of aversion, pleasure, joy or distaste, are judgment feelings that occur as the auditions of tone become an element in a higher synthesis of feeling. The perceiver of the musical tones will not, in other words, react immediately to a tone with a judgment of feeling (aversion or pleasure, joy or distaste). Judgment feelings will occur only after the perceiver has synthesized the feelings in relation to the perceived patterns of tones. The sensations associated with the original audition of the single tone (sound) will remain as an element in the final component of feeling (Process 234).

In a general sense, the satisfaction (completion) of a musical experience as an aesthetic experience (i.e., feelingful experience) is the completion of an emotional pattern. The completion of an aesthetic experience is a fact (the final component of feeling) that cannot be separated from any of its elements (a feeling whose origin is in the audition of a single tone). As individual tones are synthesized and transformed into patterns of tones, judgment feelings of joy, distaste, aversion, or pleasure are attached to the audition of tones by the individual perceiving the tones. Baser feelings become a component in the higher synthesis of to the audition of tones by the individual perceiving the tones. Baser feelings become a component in the higher synthesis of feeling. As feelings are synthesized, the perceiver makes judgments that admit the feelings into intellectual belief (value) ${ }^{2}$ (Whitehead, Process 187). The way in which a feeling becomes a belief will be explained in the next section.

\section{Different Types of Feelings in the Aesthetic Dimension of Music}

In the discussion above, feeling was described as a synthesis of the sensations associated with the relative intensities of the fundamental and a selection of its overtones. The perceived volume (absolute intensity) of a tone is a feeling. This type of feeling, is referred to by Whitehead as a simple physical feeling (Process 231-32). In general, there are two main categories of feelings: physical and mental.

The simplest type of mental feeling in music is derived from an individual's understanding of the music. In the music of Western civilization, a major scale may be sung in solfege as: do-re-mi-fa-sol-la-ti-do. Individuals who know the sound of a major scale will feel that "ti" should pull up to "do" at the end of the scale. If the scale is sung: do-re-mi-fa-sol-la-ti, and is not completed with the final 'do,' the perceiver of that experience will feel cheated-a feeling that the experience needs something else to be complete. Whitehead calls this type of feeling a conceptual feeling - a feeling for something beyond itself (Process 236-40).

2. The intellectual feeling of belief is closely related to a value experience. A musical experience as a value experience is the means by which an individual can grow in self-knowledge and self-understanding by contemplating and reflecting on felt experiences. The concept of values as derived from a musical experience will be discussed later. 
In J. S. Bach's St. Matthew Passion, Bach manipulates tonal patterns to create a mental (conceptual) feeling combined with his own proposition. The synthesis of a proposition with a baser mental feeling creates a more complex feeling - a propositional feeling. In one of the St. Matthew recitatives, the text of which is derived largely from the holy writings of the Book of Matthew, Jesus Christ states: "but flesh is weak." The chord preceding "weak" is a dominant chord, creating the feeling (conceptual feeling) that the chord should resolve to the tonic (very similar to the feeling that 'ti' should resolve to 'do' at the end of the scale). By resolving to a six chord (deceptive cadence similar to singing do-re-mi-fa-sol-la-ti-la) instead of the tonic (ti-do), the term "weak" becomes a literal proposition with the music. The tonal pattern reinforces the perceiver's feeling that flesh is weak.

Some of the other propositions in the St. Matthew Passion are usages of word painting. In the recitatives that contain the words spoken by Jesus Christ, the violins sustain high tones, representing a halo. The exception is at the end of the Passion, when Jesus is on the cross. The absence of the halo at this juncture depicts the proposition that Christ is mortal. In Bach's use of the figurative halo and his later elimination of the halo, the perceiver of the St. Matthew Passion can synthesize Bach's two propositions either to formulate or confirm the feeling (also value) that Christ has a dual station: divine and human. Bach's use of the sustained tone in the violins is both an audible and visual proposition. The whole-notes in the violin part look like a halo above the melodic recitatives of the words of Christ.

In the passage where Jesus tells his disciples that one will betray Him, the disciples' voices answer in counterpoint: "Lord is it I?" There are eleven statements of this melodic phrase, providing the perceiver with the opportunity to feel that the question is asked by eleven of the twelve disciples (all but Judas).

In the recitative in which Jesus speaks to his disciples from the Mount of Olives, the lower instruments of the orchestra play a slow, ponderous ascending scale passage, providing the perceiver with the opportunity to feel that Jesus and his disciples are ascending the Mount of Olives. In a later passage, another ascending scale passage is used in a more lyrical context, creating the image (feeling) of ascension to heaven. In another passage, as the chorus sings: "He's led away," there are heavy, measured treads in the orchestra, providing the perceiver with the opportunity to feel heavy, measured footsteps.

All figurative descriptions in the St. Matthew Passion are propositions of whether the music is true to the Christian subject matter at hand. Even in the title St. Matthew Passion the perceiver is given the means to assume an attitude of profound reverence. The opening chorus of the composition confirms the intended reverent posture, as the story of the pain and suffering of the faithful at the time of the crucifixion is laid before the perceiver. The propositions of this composition are based on whether the music is true to the words, and the words to the music.

Propositions created by word painting were excessive in the Baroque period. The visual halo was one example. Composers would sometimes sound a full chord in the middle of a single melodic line, which visually looks like a cross to the performer. When Jesus speaks of serpents in the St. Matthew Passion, some of the strings play rapid ascending and descending scale passages to create the proposition of snakes slithering. The two main types of word painting in the Baroque period consisted of imitation of natural sounds (such as bird sounds, or laughing) and imitation of physical movements (such as ascending, descending, running, walking, or falling).

Composers have used propositions in their music throughout history. The composer (or artist) "does not create a proposition out of nothing, he discovers a proposition whose intelligibility is dependent on contextual relationships” (Ryan, “Aesthetic Dimension” 88). The clearest examples of propositions in music can be seen in vocal music, opera, and various types of program music. The music of Liebestod from Wagner's opera Tristan and Isolde has been described by aestheticians as being isomorphic to the sexual climax. The proposition has been described as follows:

The patterns of rising and falling, crescendo and diminuendo, rising gradually to a climax and then concluding possess a considerable structure similarity to, or isomorphism with, the rhythm of the sexual climax (“Aesthetics” 48)

That is the proposition for that segment of the opera. The proposition may be considered true for the purposes of his discussion because it is agreed upon by aestheticians.

Richard Strauss' use of the leitmotif in his tone poems (programmatic music) represent another example of propositions that can create feelings. The programmatic element is so intricately interwoven with the leitmotivic device, that the feeling is presented to the perceiver as a basis for a proposition. In Strauss' Death and Transfiguration, for example, not only are physical elements portrayed in the leitmotivic devices but the psychological intricacies of the character are also exemplified in the manipulations of leitmotivic variations. The proposition is whether the leitmotif is true or false to the story and psychological characterization. 
Death and Transfiguration was Strauss' attempt to present the last hours of a dying man. In the opening measures of the composition, Strauss attempts to portray a man lying on a bed, weak and dying. The sporadic heartbeat is derived from an irregular rhythmic pattern that alternates between strings and tympani. The strings are also used to give an effect of pathetic sighs of the sufferer accentuated with upward twists of the flute. These particular motivic images are propositions of the physical development of the dying man. Strauss structures psychological propositions by intertwining motifs for "agony" and "the will to live" as themes which were intended to represent the dying man's childhood and youth. Norman Del Mar indicates that the thematic material in Death and Transfiguration, like many of Strauss' other works, is "intended to give a many sided character study.... The motifs... are skillfully devised with a view to characteristic development during the course of the work (Commentary 1:79-80).

The proposition in a musical composition serves as an objective factor by which the perceiver of a musical experience may distinguish aesthetic attention from non-aesthetic attention. In Bach's St. Matthew Passion, for example, Bach uses the sustained whole notes in the violins to portray a halo. Bach discovered a contextual relationship (whole notes sustained above a recitative) by which the perceiver must contemplate and recreate the proposition in his or her own experience. If the perceiver makes no decision regarding the whole notes as a figurative halo, that particular experience is not aesthetic. If the perceiver decides the proposition is a halo, the perceiver's attention becomes aesthetic, and the criterion is established for the perceiver to experience a conscious feeling (propositional feeling). The process by which the perceiver contemplates and recreates the proposition is demanding. Donald Sherburne states that

the aesthetic contemplation of an art object demands that he contemplator have the ability to seize the proposition objectified by the performance... and to recreate the proposition in his own experience. Real aesthetic experience, i.e., aesthetic recreation, requires ability, background, and hard work. Aesthetically sensitive people know better than to try to prehend art objects when they are tired and they know that aesthetic attention cannot be successfully sustained over to [sic] considerable periods of time. The effort involved in aesthetic recreation is intense and requires a combination of intellectual and affective activity. (Implications 144)

An individual experiencing the St. Matthew Passion, with its countless propositions, may experience new depths of aesthetic attention each time a new proposition felt.

As the complexity of feelings increase in a musical experience, the perceiver's feelings become conscious (i.e., the perceiver is more aware of his or her feelings, and this will involve more intellectual contemplation on the part of the perceiver).receiver is more aware of his or her feelings, and this will involve more intellectual contemplation on the part of the perceiver). The earlier examples of word painting in the Bach Passion required less intellectual contemplation than the Wagner and Strauss examples. Bach supplied the perceiver with literal propositions. In the example of Wagner's Liebestod, however, the proposition was not literal. A composer cannot completely and accurately word paint a sexual climax. For the perceiver to consider the music of Liebestod isomorphic to the sexual climax, the perceiver must use his or her imagination to create the proposition that the tonal patterns of rising and falling, crescendo and diminuendo, are isomorphic to the sexual climax. ${ }^{3}$

The perceiver's belief that the music of Liebestod is isomorphic to the sexual climax is derived from an imaginative feeling (i.e., the perceiver imagines the proposition to be true) and enters into his or her intellectual contemplation of the proposition as belief. There are two clear possibilities open to an individual's aesthetic perception of Liebestod: the perceiver may imagine Liebestod as isomorphic to the sexual climax, or the perceiver may consider Liebestod to be an expressive piece of music, conducive to enhancing the drama of a romantic opera. In this latter contemplation, the perceiver feels that the proposition of the love story is portrayed in the lush, expressive tonal patterns of the music.

With either contemplation, the perceiver experiences a feeling of belief. The individual will believe his or her own feeling of the proposition to be fact. In the example of Bach's Passion, the perceiver believes that the eleven contrapuntal statements of "Lord is it I?" are representative of the eleven disciples. In the example of Liebestod, the perceiver believes the tonal patterns of Liebestod to be isomorphic to the sexual climax. The former feeling is

3. This requires two conditions: the perceiver's background must contain the experience of a sexual climax; and the proposition must be present in the music-drama (i.e., the perceiver associates the sexual climax not only with the tonal patterns but also with the drama at that particular juncture). 
predicative or perceptive (i.e., feeling the proposition for "what is"); the latter feeling is indicative or imaginative (i.e., imagining the potential of "what might be" as fact). Whitehead refers to an intellectual feeling that has been derived from one's imagination as an intuitive judgment feeling (Process 270).In a musical experience, a Platonic ideal or universal can enter into the perceiver's belief associated with the intellectual feeling. The ideal of loyalty or patriotism, for example, may enter into the marcato tonal patterns of a Sousa march—albeit by cultural association. When the ideal of patriotism enters into the perceiver's emotional pattern of the Sousa march, the feeling of patriotism becomes a belief that the Sousa march is patriotic. 'Abdu'l-Bahá affirms the notion of universals or ideals entering into the feeling of music:

Whatever is in the heart of man, melody moves and awakens. If a heart full of good feelings and a pure voice are joined together, a great effect is produced. For instance: if there be love in the heart, through melody, it will increase until its intensity can scarcely be borne; but if bad thoughts are in the heart, such as hatred, it will increase and multiply. For instance: the music used in war awakens the desire for bloodshed. The meaning is that melody causes whatever feeling is in the heart to increase. (Compilation 8)

In accordance with the Bahá'í teachings, a feeling of patriotism can be extended to become a feeling of loyalty to, or love for the human race-provided the Bahá'í principle of the unity of humankind takes precedence over the feeling of patriotism in the heart of the individual.

One other type of music that is relevant to this discussion is absolute music (i.e., pure instrumental music with no religious or military connotations). An example of a feeling of belief derived from absolute music may be hypothesized through an individual perceiving the opening section of the second movement of Beethoven's Seventh Symphony (i.e., pure instrumental music with no religious or military associations). The first conscious feeling that the individual perceives is a feeling of growing strength. The perceiver derives the feeling of growing strength from the repetitive obstinacy of the motif in its slow but forceful rhythmic drive, the dramatic (marcato) style, and the growing and building intensity of the volume. The feeling of growing strength is an intellectual feeling derived from the perceiver's imagination in that there are no direct associations through a libretto or patriotic associations. When the individual synthesizes the feeling of growing strength with the feelings integrated from other tonal patternsspecifically patterns of tone from the minor mode, the individual may attain a feeling of forbearance. The individual may have arrived at this quality of forbearance from synthesizing a feeling of dejection from the sound patterns of the minor mode with the one of growing strength from the dynamics and style of the music. The quality of forbearance, however, is imaginative - the proposition of forbearance is not an element of the tonal patterns. "Forbearance" is a feeling of intuitive judgment, derived from the imaginative feeling of "what might be." The perceiver may have entered some associations into this feeling, such as the hardship of Beethoven's life. The relevance of this hypothetical example involving absolute music is that although the intuitive judgment is derived from an imaginative feeling, the quality of forbearance becomes a real feeling of belief for that particular individual — as real as the feeling of patriotism in the earlier example.

Individuals who understand the aesthetic dimension of music will understand how to formulate and clarify feelings, values, and beliefs. Those individuals who understand the formulation of feelings, values, and beliefs in music must necessarily understand that in an aesthetic experience, the formation of feelings, values, and beliefs involves one in a self-creative process (i.e., by means of one's volition) to recreate the propositions of the musical experience as a value experience. The process associated with the individual's recreation of the musical experience as a value experience is synonymous with the individual's self-creative process in the attainment of self-identity (i.e., self-knowledge). In the ensuing discussion, the term "self-identity" will be defined; its formation and nurturance through the aesthetic dimension of music explained; and its significance in the advancement of civilization established.

\section{Definition, Scope, and Limitation of Self-Knowledge}

Educators agree that a major task of education is to build a child's self-identity. ${ }^{4}$ One educational psychologist, Abraham Maslow, indicated that effective education in music is intrinsically closer to the attainment of learning one’s identity, as music offers a glimpse into infinite and ultimate values (Choate Documentary Report 73).

4. The term self-identity is synonymous with the terms self-knowledge, self-realization, and character. Specifically, an individual's self-identity is a receptacle for the values of each occasion of experience in his or her life; thus, self-identity is the individual's total value system. 
Music educators consider education in the aesthetic dimension of music to be the means by which people may build and nurture their self-identities (i.e., value systems). One proponent of aesthetic education, Stanley Madeja, stated:

A major task of education is the development of a value system for the student... congruent with the society in which he lives....

[Specifically], aesthetic education is...the heightening of those vital sensitivities which enable individuals to make informed judgments about things which matter to them. (CEMREL 11)

Educators agree that aesthetic as an approach to further one's self-identity signifies the attaining of selfknowledge - one of the greatest humanizing values of humankind. Educators such as Daniel Jordan have stated that a person's character or self-identity is the integration the total value system of that person. Daniel Jordan and Donald Streets explain an individual's value system in the following words:

we define values as relatively enduring organizations or complexes of information blended with actualized potentialities—-psychomotor, perceptual, cognitive, affective and volitional-which provide an orientation or predisposition to respond in a particular way to some aspect of the individual's environment, usually in terms of some purpose. They include an evaluative or judgmental element which clears the way for action. They are higher-order organizations of related attitudes centering around response possibilities to different elements of the environment. The total value system is composed of all the values integrated around fundamental aims, purposes or ultimate concerns that are inherent within the values. (Anisa Model 293)

A musical experience, as an aesthetic experience, is the means whereby an individual's beliefs and values may be clarified; makes that process of clarification synonymous with self-creativity in the emergence and furtherance of the individual's self-identity; and provides the means whereby an individual may realize the attainment of values beyond that of the musical experience. The individual who understands the aesthetic dimension of music will have the means to understand his or her self-creative process in translating the musical experience (as a value experience) into his or her total value system—-the self-identity.

\section{Values, Art, and Volition}

The values derived from music and art are different from the values derived from most other realms of experience. Art, in a general sense, is the arrangement of concrete facts, so that attention to particular values may be realized. Whitehead gives the example of a practical individual and a scholar looking at the sunset. Although they may know about the sun, the atmosphere, and the rotation of the earth, they may still miss the radiance of the sunset. The concrete facts are important, but only art can elicit attention to the preciousness of the sunset (Science 279-80). An individual's transient experience with an art object (e.g., music) is not adequate in itself for the attainment of his or her self-identity. It is not sufficient for one to select to look at the sunset. An individual must know how to attain the value of what is relevant to the preciousness of the sunset. An individual must not only learn to attain values but also must learn how to acquire and maintain values in the transient experiences (i.e., changing circumstances) of the world.

The transient value experiences provided by the individual's interaction with the art object (music) may be incorporated by the individual into his or her total value system - the self-identity. The value system that constitutes the self-identity becomes a uniform method of dealing with transient experiences. The individual's value system (character) is the major permanence of the individual—analogous to his or her soul. Bahá'u'lláh states:

Verily I say, the human soul is exalted above all egress and regress. It is still, and yet it soareth; it moveth, and yet it is still. It is, in itself, a testimony that beareth witness to the existence of a world that is contingent, as well as to the reality a world that hath neither beginning nor end. (Gleanings 161-62)

The musical experience, as an aesthetic experience, is more than a transient refreshment. It provides the soul with a permanent realization of values.

There are three phases in an aesthetic experience in which the perceiver translates the aesthetic experience into a value experience. The first stage, called the response stage, is where the individual perceiving the musical experience responds to the initial feelings (i.e., physical feelings associated with the sensations of sound; and mental feelings resulting from the composer's manipulation of tonal patterns). In the second stage, the perceiver develops 
an unconscious attitude toward the feelings (i.e., determining how the feelings are to be felt). It is in the second stage that the perceiver can shape the many diverse feelings into a unity which results in aesthetic appreciation. ${ }^{5}$ The perceiver's shaping of feeling into aesthetic appreciation is the origin of what aestheticians call "insight," and what philosophers refer to as "vision." The third stage of an aesthetic experience is the satisfaction-the completion of the emotional pattern. The perceiver synthesizes all the feelings and processes to attain a unity of feeling and value.

The self-creative process by which an individual may realize the musical experience as a value experience is relevant to the individual's exercise of volition. Bahá'u'lláh contends that "all that which ye potentially possess can... be manifested only as a result of your own volition" (Gleanings 149). In the earlier examples of "feeling" in a musical experience, the individual who aesthetically contemplated the music understood the proposition objectified by the performance, and then recreated the proposition in his or her own experience. The individual used volition to become self-creative in determining his or her own outcome of the aesthetic experience. The process associated with the individual's recreation of the musical experience as a value experience is synonymous with the individual's self-creative process in the emergence and furtherance of self-identity. An individual's volition is the key ingredient in translating the musical experience into the value experience that becomes a component of the self-identity.

\section{Implications of Music for the Advance of Humanity}

Proponents of aesthetic education agree that the aesthetic dimension of music is basic to understanding the meaning of reality. Through the aesthetic dimension of music, people may understand the meaning of reality through the experience of a higher ontology of life. From a Bahá'í perspective, a higher ontology of life means that an individual must subdue his or her powerful animalistic characteristics by developing and strengthening his or her spiritual qualities. The musical experience, as an aesthetic experience, provides the individual with the transient value experiences that nourish, refresh, and vivify the soul. From a societal perspective, a higher ontology of life is synonymous with the individual's enlightenment and refinement in the cultural activities of his or her society. The musical experience in this context, allows the individual to value the preciousness of a society's artistic and intellectual achievements.

An individual who remains ignorant of the aesthetic dimension of music (or art) will be prone to seek those cultural experiences that provide instant gratification. Those who seek experiences that provide instant gratification function on a physical or animalistic level; whereas those who seek experiences that provide the means to attain a higher ontology of life function outside the physical realm of gratification. Whitehead states:

In its lowest form, mental experience... is merely the appetition towards, or from, whatever in fact already is. The slavish thirst in a desert is mere urge from intolerable dryness.... There is in nature some tendency upwards, in a contrary direction to the aspect of physical decay. In our experience we find appetition effecting a final causation toward ideal ends which lie outside the mere physical tendency. In the burning desert there is appetition towards water, whereas the physical tendency is towards increased dryness of the animal body. The appetition towards aesthetic satisfaction by some enjoyment of beauty is equally outside the mere physical order. (Function 26)

An individual who understands and can cultivate feeling and value necessarily becomes involved in an activity of thought indicative of a noble and exalted being-as differentiated from one who functions on an instinctive animalistic level. Whitehead explains that

when we consider other humans, and animals, an analogous variation suggests itself between their average states, and between the highest stages respectively possible for different individuals. As we descend the scale, it seems that we find in the lower types a dim unconscious drowse, of undiscriminated feeling. For the lower types, experience loses its illustration of forms, and its illumination by consciousness, and its discrimination of purpose. It seems finally to end in a massive unconscious urge derived from undiscriminated feeling, this feeling itself a derivation from the immediate past. (Function 63-64)

People who are receptive to beauty and who know how to attain feelings and values can seek experiences that provide opportunities for further self-development (i.e., self-creativity in the attainment of self-identity); however,

5. Artists and musicians agree that the aesthetic ideal is unity and diversity-diversity created by variation of motivic ideas - unity created by maintaining common elements of the motifs. 
those who seek experiences that provide instant gratification are subject to consequences in two dimensions: consequences on a personal level and consequences on a societal level. On a personal level, the individual who seeks experiences that provide immediate pleasure will not have the ability to be creative in the development of selfidentity. On a broader scale, those who cannot become self-creative in the attainment of their self-identities are unable to contribute significantly to the advance of society and, in fact, are likely to become victims of the manipulative elements of society. Jordan and Streets state:

Failure to attain [the self-identity] makes a child more of a victim of his environment rather than a master over it - a prey to the manipulative elements of society and certainly someone who is not in charge of his own destiny nor attracted by the mystery of his own becoming. (Anisa Model 297)

An individual who is unable to take charge of his or her own destiny is certainly not capable of helping to shape the destiny of civilization.

The contribution the individual makes to society must begin with the individual's own self-development. Hand of the Cause of God Amatu'l-Bahá Rúhíyyih Rabbani writes in her book Prescription for Living that

unless people begin to try to know their own essential nature, to expend a portion of their energies inwardly, in self-exploration, in taking care of their own personalities and learning to master them, there cannot and will not be a permanent change for the better in human society. We have wonderful blue-prints for society, but in spite of all we do, the structure will not stand. It continually gives way, first in one place, then in another, because the building bricks cannot bear the weight. (23)

An individual's understanding of how to use the aesthetic dimension of music is a means by which the individual's self-development may take place, and subsequently the advance of civilization. Rúhíyyih Rabbani states that the "senses are doors which can lead us not only to a fuller expression of life but to a better understanding of it and a higher state of inner development" (81). Whitehead extends this sentiment, and in relation to the arts representing a higher ontological principle, states that

art and literature have not merely an indirect effect on the main energies of life. Directly, they give vision. The world spreads wide beyond the deliverances of material sense, with subtleties of reaction and with pulses of emotion. Vision is the necessary antecedent to control and to direction. (Aims 91)

One who attains expert knowledge in the aesthetic dimension of music has the means to attain greater degrees of receptiveness to beauty and humane feeling. An individual's receptivity to beauty and humane feeling is the balance needed to harness technological advances to areas that will benefit—not destroy—humanity. The author of A Nation at Risk stated that "the arts and humanities must be harnessed to science and technology if the latter are to remain creative and humane” (Gardner, 10)

\section{Conclusion}

Music is a tool by which an individual may affect his or her spiritual state and subsequently the advance of civilization; however, music cannot become a replacement for the teachings of God. 'Abdu'l-Bahá contends that "music is an important means to the education and development of humanity, but the only true way is through the Teachings of God" (Compilation 7).Music may be used as a supplement to amplify an individual's religious and moral values. 'Abdu’l-Bahá states that

musical melodies form an important role in the associations, or outward and inward characteristics, or qualities of man, for it is the inspirer or motive power of both the material and spiritual susceptibilities. What a motive power it is in all feelings of love. When man is attached to the Love of God, music has a great effect upon him. (Compilation 7)

The danger of music is that it can also affect people for evil purposes. 'Abdu'l-Bahá was quoted earlier as stating that music increases whatever purpose is $n$ the individual's heart. He gave the example of using music in war to increase the desire for bloodshed.

The teachings of God must form the basis of an individual's feelings, values, and beliefs. Music then becomes a tool by which the individual may assert his or her true spiritual nature. 'Abdu’l-Bahá states that 
some people are naturally kind, but they may be accidentally upset by a wave of anger. But if they hear music, the true nature will reassert itself. Music really awakens the real, natural nature, the initial essence (Compilation 8)

\section{Works Cited}

'Abdu’l-Bahá. Selections from the Writings of 'Abdu’l-Bahá. Trans. Marzieh Gail. Comp. Research Department. Haifa: Bahá'í World Centre, 1978.

“Aesthetics.” Encyclopedia of Philosophy. 1967 ed.

Bach, Johann Sebastian. Saint Matthew Passion. New York: Edwin F. Kalmus, n.d.

Bahá’í Writings on Music. London: Bahá'í Publishing Trust, 1973.

Bahá'u'lláh. Epistle to the Son of the Wolf. Trans. Shoghi Effendi. Wilmette: Bahá'í Publishing Trust, 1988

- Gleanings from the Writings of Bahá'u'lláh. Trans. Shoghi Effendi. New ed. Wilmette: Bahá'í Publishing Trust, 1976.

Beethoven, Ludwig van. Symphony No. 7 in A Major, Op. 92. The NBC Orchestra. RCA LM-6901.

Choate, Robert A. ed. Documentary Report of the Tanglewood Symposium. Washington: Music Educators' National Conference, 1968.

Del Mar, Norman. Richard Strauss: A Critical Commentary on His Life and Works. 3 vols. Philadelphia: Chilton Book, 1969-73.

Gardner, David P. A Nation at Risk: The Imperative for Educational Reform. Washington: Government Printing Office, 1983.

Jordan, Daniel C., and Donald T. Streets. “The Anisa Model: A New Basis for Educational Planning.” Young Children 28.5 (June 1973): 289-306.

Langer, Susanne. Feeling and Form. New York: Philosophical Library, 1953.

Madeja, Stanley S. “The CEMREL Aesthetic Education Program: A Report to the Field.” Art Education 26.6 (September 1973): 11-13.

Rabbani, Rúhíyyih. Prescription for Living. 2d ed. Oxford: George Ronald, 1978.

Reimer, Bennett. A Philosophy of Music Education. Englewood Cliffs: Prentice Hall, 1970.

Ryan, Joanne. "The Aesthetic Dimension of Process Philosophy in Alfred North Whitehead and Pierre Teilhard de Chardin and Its Significance for Education.” Diss. New York University, 1981.

Sherburne, Donald W. A Whiteheadian Aesthetic: Implications of Whitehead's Metaphysical Speculation. New Haven: Archon Books, 1970.

Strauss, Richard. Tod und Verklarung. New York: E. F. Kalmus Orchestra Scores, 1933.

Whitehead, Alfred North. The Aims of Education and Other Essays. New York: Macmillan, 1929. 
. The Function of Reason. Princeton: Princeton University Press, 1929.

. Process and Reality: An Essay in Cosmology. Corrected ed. Ed. David Griffin and Donald Sherburne. New York: Free Press, 1978.

- Science and the Modern World. New York: Macmillan, 1925. 